Summer 8-17-2018

\title{
Emergent Completion of Multistep Instructions via Joint Control
}

Megan Vosters

University of Nebraska Medical Center

Tell us how you used this information in this short survey.

Follow this and additional works at: https://digitalcommons.unmc.edu/etd

Part of the Applied Behavior Analysis Commons

\section{Recommended Citation}

Vosters, Megan, "Emergent Completion of Multistep Instructions via Joint Control" (2018). Theses \& Dissertations. 303.

https://digitalcommons.unmc.edu/etd/303

This Dissertation is brought to you for free and open access by the Graduate Studies at DigitalCommons@UNMC. It has been accepted for inclusion in Theses \& Dissertations by an authorized administrator of DigitalCommons@UNMC.For more information, please contact digitalcommons@unmc.edu. 


\title{
Emergent Completion of Multistep Instructions via Joint Control
}

\author{
by \\ Megan E. Vosters \\ A DISSERTATION
}

\author{
Presented to the Faculty of \\ the University of Nebraska Graduate College \\ in Partial Fulfillment of the Requirements \\ for the Degree of Doctor of Philosophy
}

Medical Sciences Interdepartmental Area Graduate Program

(Applied Behavior Analysis)

Under the Supervision of Professor Kevin C. Luczynski

University of Nebraska Medical Center

Omaha, Nebraska

June, 2018

Supervisory Committee:

Nicole Rodriguez, Ph.D., BCBA-D

Kathryn Peterson, Ph.D., BCBA-D

Brian Greer, Ph.D., BCBA-D

Dave Palmer, Ph.D. 


\section{ACKNOWLEDGEMENTS}

Appreciation is extended to Daniel Vosters, Maegan Pisman, and Jaimie Digby for their assistance conducting sessions or collecting data. I thank the members of my committee, Drs. Dave Palmer, Nicole Rodriguez, Kate Peterson, and Brian Greer, for their support and feedback during the course of the study and preparation of this document. Dr. Jeff Tiger, I am grateful for your continued encouragement, guidance, and friendship over the course of my graduate career. Daniel Vosters, thank you for allowing me to chase my dreams and for continuing to stand by me with unconditional love and support. I could not have done this without you.

Finally, I would like to extend my deepest appreciation to Dr. Kevin C. Luczynski.

I appreciate all that I have learned from you, and I thank you for your mentorship and encouragement throughout this project, my education, and career. Your guidance and support have profoundly influenced my development as a clinician, researcher, and teacher. 


\section{Emergent Completion of Multistep Instructions via Joint Control}

\section{Megan E. Vosters, Ph.D.}

\section{University of Nebraska Medical Center, 2018}

\section{Supervisor: Kevin C. Luczynski, Ph.D., BCBA-D}

Teaching procedures that facilitate the emergence of novel responses allow for increased efficiency, which is critical when providing early-intervention services to children with autism spectrum disorder (ASD). Three children diagnosed with ASD between 5 and 6 years old participated. In Study 1, we demonstrated functional control over the effects of teaching echoic rehearsals on the emergence of completing novel two-step instructions via joint control. In Study 2, we conducted an experimental analysis of joint control by disrupting rehearsal of the instruction and tacts of the objects in the instruction, which served as the sources of joint control. Our results support the efficacy of the procedures for establishing first-trial performance with novel instructions and indicate joint control is the behavioral process responsible for the emergent responses produced by our teaching procedures.

Keywords: autism, echoic rehearsals, emergent responding, instruction following, joint control, listener behavior, mediating behavior, multistep instructions 
TABLE OF CONTENTS

ACKNOWLEDGEMENTS.........................................................

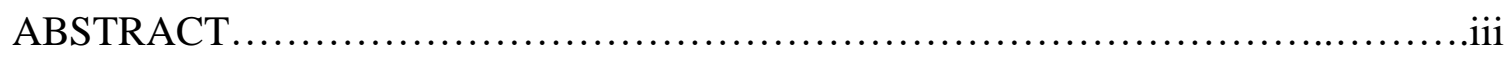

TABLE OF CONTENTS .............................................................

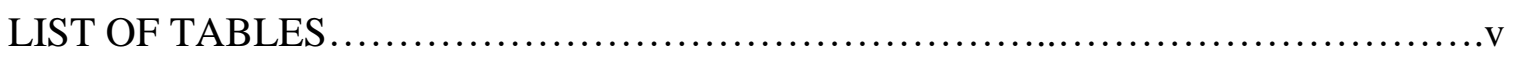

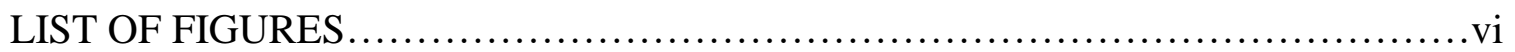

LIST OF ABBREVIATIONS ...............................................vii

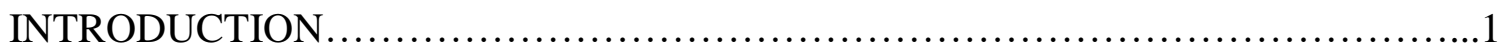

CHAPTER 1: EFFICACY OF TEACHING ECHOIC REHEARSALS ON EMERGENT

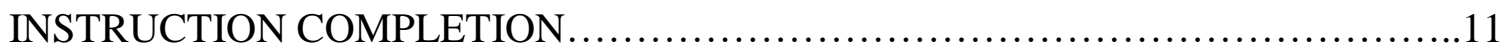

CHAPTER 2: COMPONENT ANALYSIS OF JOINT CONTROL.....................32

CHAPTER 3: GENERAL DISCUSSION ....................................41

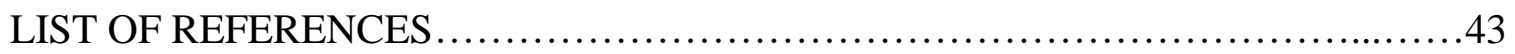




\section{LIST OF TABLES}

Table 1

Table 2

Table 3

Table 4
Receptive Discrimination of Known Actions (Instructional Frames)

Example of Two Sessions in Preteaching and Postteaching

Progression of Teaching Echoic Rehearsals

Example of Two Sessions in Two-Step Instructions with

Unknown Tacts 


\section{LIST OF FIGURES}

Figure 1

Figure 2

Figure 3

Figure 4
Efficacy, generalization, and maintenance of teaching echoic rehearsals on two-step instruction completion

Teaching echoic rehearsals

Results of the component analysis of joint control

Number of two-step instructions completed on the first trial (First-trial performance) 


\section{LIST OF ABBREVIATIONS}

ASD

DOR

IOA
Autism spectrum disorder

Differential observing response

Interobserver Agreement 
Introduction

Studies have shown instructions comprise the majority of teacher-child interactions in early education settings (Beaulieu, Hanley, \& Roberson, 2012; Ndoro, Hanley, Tiger, \& Heal, 2006). Atwater and Morris (1988) conducted a descriptive assessment of teacher-child interactions in early education settings and found preschool teachers delivered, on average, seven instructions every 4 min. It is not surprising that over 3,000 kindergarten teachers ranked following instructions as one of their top five school-readiness skills (Lin, Lawrence, \& Gorrell, 2003). However, some children who are diagnosed with a developmental disability, such as autism spectrum disorder (ASD), do not complete novel instructions due to skill deficits. The skill deficits may be related to, in part, attending to the multiple, brief verbal stimuli that comprise an instruction (e.g., "Put your backpack in cubby"); the absence of discriminative control by the objects (e.g., "backpack," "cubby") and frames (e.g., "Put your [object] in [object]"); or both (Striefel, Wetherby, \& Karlan, 1976; Sundberg \& Sundberg, 2011). To address these skill deficits, researchers have implemented prompting and reinforcement procedures that have led to the completion of novel instructions on the first attempt, henceforth called first-trial performance (Frisch \& Schumaker, 1974; Striefel et al., 1976; Whitman, Zakaras, \& Chardos, 1971).

Frisch and Schumaker (1974) taught children with developmental disabilities to complete instructions composed of one of three instructional frames (i.e., actions): "Put the (object) on the (object)," "Put the (object) next to the (object)," and "Put the (object) under the (object)." During teaching, instructions were spoken in the presence of target and nontarget (i.e., distractor) objects, and the objects were rotated across different 
actions to ensure the children learned to discriminate both the action and the objects. In other words, the action and objects functioned as distinct sources of stimulus control in that the action exerted discriminative control over how the children responded to the objects (e.g., the pail was placed on, instead of next to, the chair). Next, objects not associated with teaching were included in instructions with the same actions, which made the instructions novel. Both children exhibited first-trial performance with these untrained instructions. Striefel et al. (1976) used similar procedures to teach 144 actionobject instructions (e.g., "Point to [glass]," "Pound with [spoon]," and "Push [comb]"). Like Frisch and Schumaker, they found all children exhibited first-trial performance with novel instructions after listener responses had been taught for each action and each object.

Both studies demonstrated the effects of prompting and reinforcement on producing first-trial performance with novel instructions. However, neither study offered a behavior-analytic account of the mechanisms by which the procedures produced firsttrial performance. The authors, instead, suggested their performance was a product of the children learning a “. . . complex combination decoding rule” (Striefel et al., 1976, p. 258) or ". . . the gradual formation of rules used in a generative manner" (Frisch \& Schumaker, 1974, p. 620). It is important to provide an interpretation of the outcomes that is conceptually systematic and falsifiable because doing so may identify factors that explain inconsistent effects of the independent variable across children (i.e., interpreting variance; Palmer, 2004).

An alternative behavior-analytic interpretation of first-trial performance in Frisch and Schumaker (1974) and Striefel et al. (1976) involves what Lowenkron (1998) called 
joint control, which is, " ... a discrete event, a change in stimulus control that occurs when a response topography, evoked by one stimulus and preserved by rehearsal, is emitted under the additional control of a second stimulus" (p. 332; see also Lowenkron, 2006). Joint control offers a parsimonious and conceptually systematic interpretation of first-trial performance with instructions. For example, after hearing an instruction (e.g., "Put the [pail] on the [chair]"), a child may repeat the instruction overtly or covertly as an echoic. When an object (e.g., pail) evokes a tact ("pail") of the same topography as the rehearsed instruction (i.e., self-echoic), the joint echoic-tact control evokes picking up the pail. Then, placing the pail on the object in the way that evokes a tact in the same form as the rehearsed instruction (“...pail on the chair”). When a component of the instruction (action and object) evokes a particular response, the joint control of echoic and tact repertoires facilitates emergent performance across countless permutations of actions and objects.

Causin, Albert, Carbone, and Sweeney-Kerwin (2013) evaluated procedures for teaching echoic rehearsals to facilitate the selection of pictures in sequences from an array based on three-word or four-word spoken sequences with children diagnosed with ASD. Although the authors' experimental preparation and teaching procedures were informed by the conceptualization of joint control, functional control over the effects of teaching was not shown due to the delayed, inconsistent mastery of untrained sequences, and the gradual improvement obtained with emergent sequences presents an interpretive challenge. The latter concern may have been due to inconsistent rehearsal performance during the emergent tests, but trial-by-trial measures on correct rehearsal of the instruction were not reported. 
Although Frisch and Schumaker (1974) and Striefel et al. (1976) demonstrated effective procedures for establishing first-trial performance and Causin et al. conducted a preliminary evaluation under the conceptual framework of joint control, no study addressed several types of instructions that children routinely experience at home and school. First, the authors tested only single-step instructions in which the objects required to complete the actions were immediately available in front of the children. Multistep instructions are, however, common at home and school and, for this reason, have been incorporated in assessments and interventions (e.g., Beaulieu \& Hanley, 2014). Second, the completion of multistep instructions sometimes requires transitioning to different parts of a room or building, during which there is a delay from hearing the instruction and encountering the objects to complete it.

Delays have been shown to interfere with instruction completion. In a translational study, Lowenkron (1988) addressed poor performance due to delays by teaching rehearsal of the sample stimulus in a delayed identity-matching task. Four teenagers diagnosed with intellectual disabilities were taught unique hand signs to tact arbitrary shapes, which were presented as sample stimuli, and to maintain the hand sign over delays until shapes were presented as comparison stimuli. The hand sign (a) functioned as a tact of the shape when presented as the sample stimulus, (b) maintained the stimulus control of the sample shape over the delay as a rehearsal, and (c) facilitated selection of the comparison shape that evoked the same tact. Teaching rehearsals should be extended to children with ASD in the context of multistep instructions with delays. Teaching echoic rehearsals, like hand signs, also should serve to maintain stimulus control over delays and thereby facilitate the completion of multistep instructions via 
joint control. However, no study has taught echoic rehearsals to facilitate first-trial performance of completing instructions and no study has taught the completion of multistep instructions with delays.

In Study 1, we taught echoic rehearsals to children with ASD and evaluated the effects of the teaching on the completion of two-step instructions with delays using a two-room arrangement. That is, we delivered a two-step instruction in one room and had the children walk down a 10-m hall to a room with the objects needed to complete the two-step instructions. We assessed the generality of the intervention effects across settings and people and maintenance of instruction completion over time. In Study 2, we extended translational research showing that joint control facilitates emergent responding (Lowenkron, 1984; 1988; 2006) by conducting an experimental analysis of both sources of joint control (echoic rehearsals and tacts).

\section{Participants and Setting}

\section{General Method}

Three boys diagnosed with ASD participated in both studies, Bruce (6 years, 3 months), Clark (5 years, 2 months), and Peter (5 years, 1 month). The selection of children was based on (a) a records review of their mastered skills from the Assessment of Basic Language and Learning Skill - Revised (ABLLS-R; Partington, 2006), (b) educational goals, and (c) performance on our preassessments. We included children who, first, had a relatively well established listener and speaker repertoire. That is, they acquired new tacts without intensive teaching (ABLLS-R Skill G10), tacted at least 250 objects (Causin et al., 2013), and responded to instructions with actions ("Put [object] on [object]"). Second, we selected children who complied with single-step instructions (e.g.,

"Touch the book."), which ruled out concerns regarding noncompliance and indicated 
discriminative control of the action (e.g., touch) and object (e.g., book). Third, we ensured the children's echoics were under the control of a rehearsal prompt (i.e., experimenter pointed index finger toward her mouth and then pointed finger at the child to evoke echoics). Fourth, children included in our study responded to joint control as a discriminable event. Fifth, we included children who could echo four-word phrases (e.g., "The little purple book" or "The giant red apple"). The latter two criteria were determined through screening and preassessments described below. All preassessments and teaching sessions were conducted in a small room with a child-sized table, two childsized chairs, and storage bins. All preteaching and postteaching sessions were conducted in a clinic; within two rooms separated by a 10-m hallway. Blocks of two to seven sessions were conducted three to five days per week.

\section{Joint Control Screening Assessment}

We used the screening assessment to identify children who could discriminate the onset of joint echoic-tact control (i.e., passed the first part of the assessment without a delay) but did not rehearse the instruction over a delay and exhibited incorrect responses (i.e., failed the second part of the assessment with a 10-s delay). After identifying objects the children could tact, eight were selected and placed equally spaced apart in two horizontal rows of four; the objects were rotated across trials. Each session included five trials. At the start of a trial, we used a cardboard box $(35.56 \mathrm{~cm}$ by $45.72 \mathrm{~cm})$ to cover the objects. We then gave an instruction and immediately prompted a differential observing response (DOR; i.e., the child repeated the instruction), with the latter geared toward ruling out incorrect responses due to poor attending. A correct response to the instruction produced brief praise (e.g., "nice job") and an edible that was identified by a preference 
assessment. We did not provide corrective feedback after an incorrect response or no response.

In the first part of the assessment, we screened for children who could respond to joint echoic-tact control for novel listener responses in a receptive-identification preparation, which was similar to Causin et al. (2013). We assessed whether the child could hand the experimenter three of the eight objects in a specific order with no delay. We chose this target response because it seemed unlikely children had a history of reinforcement for selecting the objects in these sequences. While seated at a table, we gave an instruction with one action and three objects (e.g., "Give me the [apple], [cup], and [horse]"). We immediately prompted a DOR and then removed the cover allowing the child an opportunity to respond to the instruction. A correct response included handing over the three specified objects in sequential order within $20 \mathrm{~s}$. Children who responded correctly on four of five trials participated in the second part of the assessment because we considered this performance to indicate that the child could discriminate the onset of joint control. In the second part of the assessment, we screened for children who could respond to joint control over a delay. The procedures were identical with the foregoing assessment except the cover on the objects was removed $10 \mathrm{~s}$ after the DOR. Children who responded correctly on one or fewer trials participated in Studies 1 and 2.

\section{Assessment of an Echoic Repertoire of Words and Phrases}

We conducted two echoic assessments to characterize the children's incoming echoic repertoire. In both assessments, we used a rehearsal prompt and delivered brief praise and an edible after a correct echoic. After an incorrect response (omission of words or adding a word), we moved to the next echoic (i.e., no error correction); after no 
response within $5 \mathrm{~s}$, however, we repeated the word or phrase a second time to rule out the possibility the absence of a response was due to poor attending on a trial. We adopted Esch, Esch, McCart, and Petursdottir's (2010) criterion to (a) progress to the next level, which was correctly echoing two of three-word strings, and (b) end the assessment, which was errors on two of three-word strings at a level.

First, we verified children could echo at least three words in a row, which was a prerequisite to our teaching procedures. We then assessed how many words a child could echo beyond that number to characterize their echoic repertoire. In each trial, we prompted the child to echo a number of words that progressively increased across trials, starting with a string of two words (hereafter called Level 2, because we tested two words; e.g., "ball, kitty"). Each level consisted of three-word strings that were randomly generated, and each word string in a level contained words that started with a different letter and included one two-syllable word.

Second, we assessed whether children could echo phrases that approximated the number of words in the two-step instructions we used during preteaching and postteaching. To match the number of syllables to the two-step instructions, each phrase contained at least two words with two syllables, and there were three phrases at each level. In each trial, we prompted the child to echo phrases with a progressively increasing number of words, starting with four-word phrases (Level 4; e.g., "Big yellow cat meows"). We used phrases that differed from the instructional frames used in preteaching and postteaching to (a) minimize exposure to the instructional frames and (b) avoid the potential undesirable effects of establishing a history of delivering the instructions but not allowing the child to complete them. Bruce echoed four-word strings and nine-word 
phrases. Peter echoed four-word strings and seven-word phrases. Clark echoed threeword strings and five-word phrases.

\section{Response Measurement and Interobserver Agreement}

All sessions were videotaped for scoring procedural fidelity and collecting interobserver agreement (IOA). We scored correct and incorrect instructions and correct and incorrect echoic rehearsals on a trial-by-trial basis in real-time using paper and pencil. A correct instruction included completing the instruction in sequential order within $45 \mathrm{~s}$. An incorrect instruction included errors in the form of completing the correct action but with an incorrect object, completing a wrong action but with the correct object, or completing the correct steps in the instruction (action and object) but in the wrong sequence. Correct echoic rehearsals included the child echoing the instruction with fewer than $3 \mathrm{~s}$ between rehearsals from the time the instruction was delivered until the child encountered the objects necessary to complete the instruction. We chose a dense interrehearsal interval to increase the likelihood the child would be rehearsing the instructions as he encountered the objects. Incorrect echoic rehearsals were scored when the child changed or omitted words that altered the function of the instruction, or echoed the steps in the wrong sequence.

During Study 1, a second observer independently collected IOA on 53\%, 68\%, and $74 \%$ of sessions for Bruce, Peter, and Clark, respectively and IOA was collected across all phases for at least $29 \%$ per phase. Agreement scores were calculated by comparing each observer's records on a trial-by-trial basis. Agreements were defined as both observers scoring the same response for instructions and rehearsals. The number of trials scored as agreements were summed and divided by the number of trials in a session, 
and this quotient was converted to a percentage. Mean agreement across all sessions and children for scoring instructions and rehearsals was 99.6\% (range, 84\%-100\%). Procedural fidelity was scored on at least $34 \%, 36 \%$, and $29 \%$ of sessions across all phases for Bruce, Peter, and Clark, respectively. Procedural fidelity measures were calculated on a trial-by-trial basis and tailored for each phase. We scored the categories of (a) arranging the materials correctly, (b) conducting a single-selection reinforcer assessment before each trial or session, (c) securing attending before instruction delivery, (d) delivering the programmed instruction, (e) providing the programmed consequences, and (f) rearranging objects between trials. Procedural fidelity scores were calculated by dividing the number of procedures implemented correctly by the total number of opportunities in a session, and this quotient was converted to a percentage. Based on video review, mean fidelity across all sessions, procedures, and children was $99 \%$ (range, $92 \%-100 \%)$.

During Study 2, a second observer independently collected IOA on 43\%, 38\%, and $33 \%$ of sessions for Bruce, Peter, and Clark respectively. IOA was scored for at least $25 \%$ of sessions across all phases for Bruce and Peter; however, due to corrupted videos, IOA was not collected during the unknown tact phases for Clark. Mean agreement across all sessions and children for scoring instructions was 100\%. Mean agreement across all sessions and children for scoring rehearsals was 98\% (range, 84\% - 100\%). Procedural fidelity was scored on $25 \%, 56 \%$, and $21 \%$ of sessions for Bruce, Peter, and Clark, respectively. Procedural fidelity was scored in at least $25 \%$ of sessions across all phases for Bruce; however, due to corrupted videos, procedural fidelity was not scored during the interruption and unknown tact phases for Clark and the interruption phase for Peter. 
Based on video review, mean fidelity across all sessions, procedures, and children was 98\% (range, $83 \%-100 \%$ ); the few errors pertained to not conducting the single-selection reinforcer assessment (described below) before each trial.

\section{CHAPTER 1: Efficacy of Teaching Echoic Rehearsals on Emergent Instruction Completion}

We used a multiple baseline design across participants to demonstrate experimental control over the effects of teaching echoic rehearsals on the emergence of completing novel combinations of two-step instructions. To enhance the ecological validity of the delay between hearing an instruction and completing it, we used a tworoom arrangement in preteaching and postteaching. We delivered an instruction in one room and had the child walk down a $10-\mathrm{m}$ hall to a room with the objects needed to complete it. In teaching, we taught rehearsals across a set of four steps that were progressively more difficult with the ultimate goal of approximating the conditions in which two-step instructions were delivered in preteaching and postteaching.

\section{Verifying Requisite Discriminations via Preassessments}

We identified objects the child could tact. Next, we verified each child could receptively identify the objects (auditory-visual discrimination). Finally, we verified the six instructional frames, each composed of a different action, exerted discriminative control over each child's behavior. For each preassessment, a correct response was defined as a correct tact, selection, or action within $5 \mathrm{~s}$ of the instruction. A correct response produced brief praise and an edible, which was delivered according to the children's schedule of reinforcement programmed in their early-intervention services (variable-ratio 4 and variable-ratio 8). We did not provide corrective feedback after an 
incorrect response. During both receptive-discrimination assessments, we prompted a DOR to rule out that incorrect responses were due to poor attending.

Tact assessment to identify known objects. We identified 30 objects each child could tact, described as known objects. We randomly selected 18 of the known objects to use in the two-step instructions programmed during preteaching and postteaching; we used the remaining 12 known objects during teaching. We assessed objects from a set of 100 pictures composed of common objects that young children are likely to encounter (e.g., car, house, bed, book). During each trial, we held an object and said, "What is it?" We presented each object at least once. If the child did not respond to the first presentation within $5 \mathrm{~s}$, we re-presented the same object a second time.

Receptive discrimination of known objects. We verified the child could hand the experimenter known objects after hearing the name of the object ("Hand me [ball]") to rule out that incorrect responses during preteaching and postteaching were due to a limited listener repertoire. During each trial, eight objects were presented in two horizontal rows of four objects equally spaced apart, with seven objects serving as incorrect selections on a trial; the eight objects in the array were exchanged with another eight objects until all 30 objects were assessed. The objects were assessed in a randomized manner across trials and each object was assessed twice.

Receptive discrimination of known actions (instructional frames). We verified the children could engage in each of the six spoken actions that comprised our instructional frames. These actions were part of the two-step instructions used in preteaching and postteaching (see Table 1). Each action was assessed in the presence of ten objects to ensure correct responses were due to the discriminative control of the 
spoken action and not under faulty stimulus control of the presence or placement of a particular object (Stephenson \& Hanley, 2010; Sy, Donaldson, Vollmer \& Pizarro, 2014). Ten objects, which remained constant across trials, were presented in two horizontal rows of four (two objects were placed inside other objects to create the opportunity for the target action "Take out [object]"); the placement of the objects was rotated across trials. The actions were assessed in a randomized manner across trials and each action was assessed twice.

Table 1

Receptive Discrimination of Known Actions (Instructional Frames)

\begin{tabular}{|c|c|}
\hline Instruction 1 & Instruction 2 \\
\hline "Bring me [towel]." & "Bring me [glasses]." \\
\hline "Take out [block]." & "Take out [car]." \\
\hline "Pick up [pillow]." & "Pick up [bed]." \\
\hline "Put [duck] in [bed]." & "Put [glasses] in [bowl]." \\
\hline "Put [block] on [towel]." & "Put [duck] on [pillow]." \\
\hline "Put [glasses] under [bowl]." & "Put [car] under [bed]." \\
\hline
\end{tabular}

\section{General}

We included instructions that, arguably, were challenging to complete yet are commonly used with elementary-aged children. Our two-step instructions entailed completing (a) different actions with different objects (multistep instruction), (b) the instruction in a room that was separated by a $10 \mathrm{~m}$ hallway from the room in which the 
instruction was heard, (c) each step of the instruction in a different area of the room, and (d) the steps in the specified sequence.

We created two-step instructions in the following manner. First, we combined one of three single-step instructions that included one action and one object ("Bring me [object]," "Take out [object]" and "Pick up [object]") with one of three single-step instructions that included one action and two objects ("Put [object 1] in [object 2]," "Put [object 1] under [object 2]," "Put [object 1] on [object 2]"). This produced three two-step instructions (e.g., "Bring me [object]; put [object 1] in [object 2]”). Second, for each twostep instruction, we switched the sequential order of the instructional frames to create six two-step instructions that were delivered every session (see example in the first column of Table 2). The instructional frames that comprised the six two-step instructions did not change across sessions (i.e., we did not program all permutations of combining the single-step instructions); for example, the two-step instruction of "Bring me [object]; put [grapes] in [bag]" was programmed in every session. Third, we randomized the order in which we delivered the six two-step instructions across sessions, and we assigned the 18 objects to different instructions (see example in second column of Table 2). Fourth, after randomly assigning the objects to an instruction, we did not program instructions that were impractical or nonsensical to complete (e.g., putting the sink in the table). These procedures produced 61, 52, and 73 novel two-step instructions for Bruce, Peter, and Clark, respectively. We did not reset the placement of the objects in the room during a session; as a result, all 18 objects were used only once in each session. Although we did not reset the room between instructions, 60 objects were always present throughout the room (i.e., 18 target objects used in the instructions and 42 distractor objects). Fifth, the 
objects in the first and second steps of an instruction were on opposite sides of the room, so the child had to cross the room in order to complete both steps of an instruction. Sixth, we attempted to avoid common two-step instructions that may be delivered (e.g., "Get your backpack; put on your coat") to minimize threats to internal validity related to extraexperimental learning interacting with the effects of our teaching procedures.

Before every trial or session, based on the results from a multiple-stimuluswithout-replacement assessment (DeLeon \& Iwata, 1996), we conducted a singleselection preference assessment with a child's five top-ranked items. The child made a selection among the five items, which were presented in a row equally spaced apart. The item selected was the reinforcer for the trial or session (Hoerger \& Mace, 2006). Before each session, we walked throughout the room and prompted the child to tact the 18 known objects ("What is it?" while pointing to objects) so the child was shown the location of the objects; brief praise was provided on a fixed-ratio 2 schedule. 


\section{Table 2}

\section{Example of Two Sessions in Preteaching and Postteaching}

\begin{tabular}{|c|c|c|}
\hline Trial & Session 1 & Session 2 \\
\hline 1 & "Bring me [crayon]; Put [grapes] in [bag]." & "Put [baby] on [drum]; Take out [truck]." \\
\hline 2 & "Take out [baby]; Put [truck] under [sink]." & "Put [spoon] under [bag]; Pick up [phone]." \\
\hline 3 & "Pick up [spoon]; Put [lamp] on [drum]." & "Take out [keys]; Put [lamp] under [book]." \\
\hline 4 & "Put [phone] in [tub]; Bring me [blanket]." & "Bring me [dino]; Put [blanket] in [sink]." \\
\hline 5 & "Put [keys] on [book]; Take out [bread]." & "Pick up [crayon]; Put [grapes] on [chair]." \\
\hline 6 & "Put [dino] under [chair]; Pick up [cup]." & "Put [bread] in [tub]; Bring me [cup]." \\
\hline
\end{tabular}




\section{Preteaching and Postteaching}

In-clinic. We delivered instructions in a room separated by a hallway from the room with the objects to complete the instruction. We initiated a trial by saying a twostep instruction and then immediately prompting a DOR to ensure the child attended to the instruction. If the child did not emit a correct DOR, the experimenter prompted the child to echo each instructional frame (action) separately ("Take out [ball]" and then "Put [marble] in [cup]"), and then the experimenter repeated the two-step instruction.

In-home or in-classroom (generalization probes). This condition served as a generality test of whether our teaching procedures would lead to instruction completion across settings and people of applied significance. We asked Bruce's and Peter's caregivers to identify six two-step instructions that were socially significant to their child's daily routine. We confirmed the child could tact the objects in the instructions as described in the tact preassessment. The procedures were identical with those described with the experimenter in the clinic, except the caregiver delivered the instructions in their home. The caregiver wore a Bluetooth headset or earbuds connected to a phone through which the experimenter remotely (from the medical center) guided when and how the caregiver delivered the instructions to promote high procedural fidelity. Sessions were recorded via a high-definition webcam (Logitech C525) connected to a laptop computer. We guided the caregiver remotely, instead of in their home, so any stimulus control exerted by the experimenter's presence that had been established during teaching would not influence the child's performance. Because in-home generalization tests could not be scheduled with Clark's caregivers in a timely manner, we tested generalization in his classroom; an adult who was unfamiliar to Clark delivered instructions. 


\section{Teaching Echoic Rehearsals}

We taught echoic rehearsals across four steps. Each step progressively emulated the situation in which instructions were delivered during preteaching (see description in Table 3). All teaching steps were conducted at a child-sized table in a different room than the room in which preteaching and postteaching took place. Moreover, none of the objects in preteaching and postteaching were used during teaching. There were six trials in every session, and the mastery criteria to progress to the next step was $100 \%$ of trials with a correct instruction and rehearsals across two consecutive sessions. During all steps, if echoic rehearsals did not continuously occur $(\leq 3 \mathrm{~s}$ interrehearsal interval $)$ or the child made an incorrect rehearsal, the experimenter immediately re-presented the same instruction to start the trial again (henceforth described as restarts). The experimenter continued this procedure until the child emitted correct rehearsals or eight restarts of the instruction were conducted, which terminated the trial. If the child emitted correct rehearsals but an incorrect instruction, the experimenter did not deliver reinforcement and proceeded to the next trial. After each trial, the experimenter rotated the objects under the cardboard cover (i.e., out of the child's view). 
Table 3

Progression of Teaching Echoic Rehearsals

\begin{tabular}{|c|c|c|c|c|c|c|}
\hline Conditions & Instruction & $\begin{array}{c}\text { \# of } \\
\text { Different } \\
\text { Frames }\end{array}$ & Delay & & Delay & \\
\hline Baseline & $\begin{array}{l}\text { "Bring me [car]; Put } \\
\text { [ring] in [crib]." }\end{array}$ & 6 & $10 \mathrm{~s}$ & $\begin{array}{c}\text { Response } \\
\text { Opportunity }\end{array}$ & $10 \mathrm{~s}$ & $\begin{array}{c}\text { Response } \\
\text { Opportunity }\end{array}$ \\
\hline \multicolumn{7}{|l|}{$\begin{array}{l}\text { Teaching } \\
\text { Step }\end{array}$} \\
\hline 1 & $\begin{array}{l}\text { "Hand me [sock], [bear], } \\
\text { [egg]." }\end{array}$ & 1 & $10 \mathrm{~s}$ & $\begin{array}{l}\text { Response } \\
\text { Opportunity }\end{array}$ & & \\
\hline 2 & "Put [duck] on [plate]." & 3 & $10 \mathrm{~s}$ & $\begin{array}{l}\text { Response } \\
\text { Opportunity }\end{array}$ & & \\
\hline 3 & $\begin{array}{l}\text { "Put [sock] in [cup]; } \\
\text { Bring me [egg]." }\end{array}$ & 6 & $15 \mathrm{~s}$ & $\begin{array}{l}\text { Response } \\
\text { Opportunity }\end{array}$ & & \\
\hline 4 & $\begin{array}{l}\text { "Bring me [car]; Put } \\
{[\text { ring] in [crib]." }}\end{array}$ & 6 & $15 \mathrm{~s}$ & $\begin{array}{c}\text { Response } \\
\text { Opportunity }\end{array}$ & $15 \mathrm{~s}$ & $\begin{array}{c}\text { Response } \\
\text { Opportunity }\end{array}$ \\
\hline
\end{tabular}

Note. The third column indicates the number of different instructional frames that we rotated in a random and balanced manner in a six-trial session. We rotated 18 objects within and across frames. 


\section{Baseline: Two-step instructions with two varying actions and three varying objects;} sequential completion of both steps. The construction of the two-step instructions was the same as used in preteaching and postteaching. Twelve objects were aligned in two horizontal rows of five (two objects were placed in other objects) under the cover. The cover allowed us to (a) program periods during which completing the instruction was not possible because the objects were unavailable and (b) rapidly cover and uncover all of the objects simultaneously. As verified via preassessments, the 12 objects were mastered as tacts, echoics, and receptive-identification targets.

With the objects covered and while seated at a table, we delivered a two-step instruction and immediately prompted the child to echo the instruction once. We programmed a 10-s delay until the cover was removed and objects were available. After an incorrect response, correct response, or $5 \mathrm{~s}$ elapsed without a response, we covered the objects for another $10 \mathrm{~s}$ before providing an opportunity to complete the second instruction. We programmed delays to simulate the time associated with searching for objects in a room when completing two-step instructions in applied situations. A correct instruction was followed by praise and an edible. An incorrect instruction did not produce reinforcement, and the next trial was initiated.

\section{Teaching-Step 1: One-step instructions with one invariant action and three} varying objects. We taught the child to rehearse an instruction over a 10-s delay and reinforced the selection of three objects in the sequence that matched the rehearsal. Each session consisted of instructions with the invariant action "Hand me [object 1], [object 2], and [object 3]" (Causin et al., 2013). To create the instructions for a session, we, first, used a web application (random.org) to randomly generate six three-object sequences 
from the 12 objects. Second, we replaced any sequence that (a) included two or more of the same objects as in the preceding instruction or (b) had the same first object as in the preceding instruction. The experimenter delivered an instruction while using a rehearsal prompt to evoke rehearsals in the absence of objects. The rehearsal prompt involved repeatedly pointing at the child throughout the delay, and we allowed the child to dictate the pace of the rehearsals. After $10 \mathrm{~s}$ of rehearsals, the experimenter removed the cover over the two rows of five objects to allow the child an opportunity to respond.

\section{Teaching-Step 2: One-step instructions with one varying action and two}

varying objects. We taught the child to discriminate and respond to both the action and the objects in the instruction. The procedures were the same as the previous step, except all instructions included different actions and two objects (e.g., "Put [doll] under [bridge]," or "Put [car] on [book]").

\section{Teaching-Step 3: Two-step instructions with two varying actions and three} varying objects; simultaneous completion of both steps. We taught the child to rehearse two-step instructions that were equal in the number of actions and objects to those in preteaching and postteaching before programming a delay between response opportunities (i.e., see Step 4 for sequential completion). The procedures were the same as the previous step, except all instructions included two instructional frames (e.g., "Put [dog] in [truck]; bring me [book]") and the single delay was increased to $15 \mathrm{~s}$. If the child met the restart criterion to end a trial due to incorrect rehearsals on $50 \%$ or more of trials during the first session, we taught echoics in a separate teaching condition (described next).

Teaching echoics of two-step instructions (Clark). To teach echoics of the steps, 
we prompted the child to echo the first instruction and then the second instruction separately and then both instructions successively, which we described as one-step echoics before two-step echoics. If the child made an error when prompted to echo the two-step instruction, we prompted echoics of the single-step instructions separately before prompting the two-step instruction again. The trial ended after the child echoed the two-step instruction or five restarts (echoic errors) occurred. After four consecutive sessions with 5 of 6 correct echoics of the two-step instruction (our mastery criteria), we only prompted the child to echo the two-step instruction, (two-step echoics). When the child met our mastery criterion for reliably echoing the two-step instructions, we returned to teaching-step 3.

\section{Teaching-Step 4: Two-step instructions with two varying actions and three} varying objects; sequential completion of both steps. The session arrangement and object presentation were identical with baseline. We prompted the child to rehearse each two-step instruction over a 15-s delay, provided an opportunity to complete the first instruction, programmed a second 15-s delay, and then provided an opportunity to complete the second instruction.

\section{Results and Discussion}

Bruce, Peter, and Clark's performance during preteaching and postteaching are depicted in Figure 1. The percentage of trials with correct two-step instructions and echoic rehearsals are depicted in two separate panels for each child. Near-zero levels of instruction completion were observed for all children during preteaching in-clinic and preteaching in-home (Bruce and Peter) and preteaching in-classroom (Clark). Correct echoic rehearsals were absent during preteaching for all three children. 


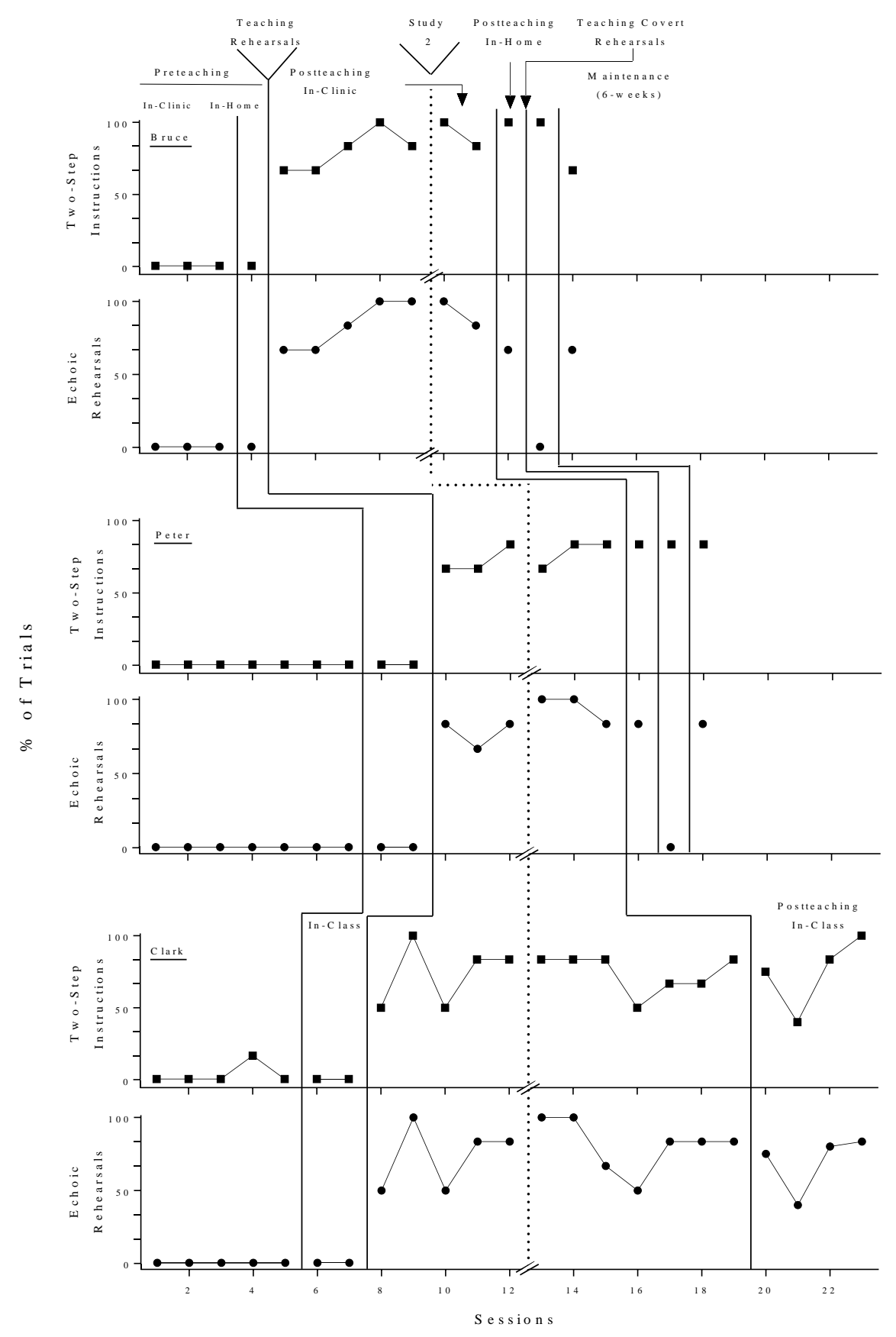

Figure 1. Percentage of trials with correct two-step instructions and echoic rehearsals during Study 1 for Bruce, Peter, and Clark. 
Next, we systematically taught rehearsals (Figure 2). Instructions are denoted by closed squares and prompted-correct rehearsals are denoted by open circles. We scored a prompted-correct rehearsal when the child rehearsed the instruction nearly continuously between the instruction delivery and until the cover over the objects was removed on the first attempt (i.e., there were no restarts). In baseline, all three children exhibited zero to low levels of completing instructions, which replicated the poor performance obtained in preteaching. In teaching-step 1, all children met the mastery criterion, but each exhibited different error patterns. Bruce exhibited near perfect prompted-correct rehearsals with some variability in completing instructions, which suggests Bruce's rehearsals did not reliably serve as verbal stimuli to facilitate joint control. By contrast, Peter completed nearly all instructions and, initially, exhibited a moderate level of prompted-correct rehearsals, which indicated Peter's rehearsals served as a source of stimulus control but he did not always engage in correct rehearsals. Clark initially exhibited both errors as shown by the moderate, variable patterns of instruction completion and prompted-correct rehearsals. In teaching-step 2, all three children quickly met the mastery criterion.

In teaching-step 3, we increased the delay to $15 \mathrm{~s}$ and progressed from single-step instructions to two-step instructions. This teaching step led to lower, variable levels of prompted-correct rehearsals for all children. In addition, in approximately the first half of sessions, the children did not rehearse after the cover was removed; instead, the child rehearsed the instruction over the 15-s delay, which met our definition of a promptedcorrect rehearsal; when the cover was removed at the 15-s mark, however, the child stopped rehearsing. As a result, the child completed the first step but then made an error with the second step, which was likely due to the absence of a proximal rehearsal of the 
second step of the instruction. Based on a within-session analysis (Fahmie \& Hanley, 2008 ), this error occurred on $80 \%, 58 \%$, and $76 \%$ of all of the trials with an incorrect instruction during teaching-step 3 for Bruce, Peter, and Clark, respectively. After several teaching sessions, the children continued to rehearse the instruction after the cover was removed and after they completed the first step; in doing so, the co-occurrence of rehearsals and instruction completion contacted reinforcement. For Clark in teaching-step 3, he never correctly rehearsed the two-step instruction without restarts and met the maximum number of restarts on three trials in the first session. Therefore, we conducted echoic teaching in separate sessions (fourth panel, Figure 2). We taught echoics of the same instructional frames used in teaching-step 3 but with different objects. After Clark progressed across the two echoic-teaching phases, we returned to teaching-step 3 , and he met the mastery criterion.

In teaching-step 4, the children completed each instruction of the two-step instructions across two 15-s delays, which matched the procedures in baseline. During this step, the children practiced rehearsing the instruction over the second 15-s delay after completing the first instruction. The primary error was not rehearsing the instruction across the second delay for all three children, which was most evident for Bruce who exhibited a variable level of prompted-correct rehearsals. However, when Bruce correctly rehearsed after a restart, he completed the instruction (black squares at 100\%) for most sessions. In summary, after meeting the mastery criteria for teaching-step 4, first, the children learned to reliably rehearse a two-step instruction over the initial 15-s delay. Second, the children learned to serve as a reliable listener to their self-echoic rehearsal when the objects were available. Third, the children learned to re-initiate rehearsal of the 
instruction after completing the first step and maintain the rehearsal over another 15-s delay.
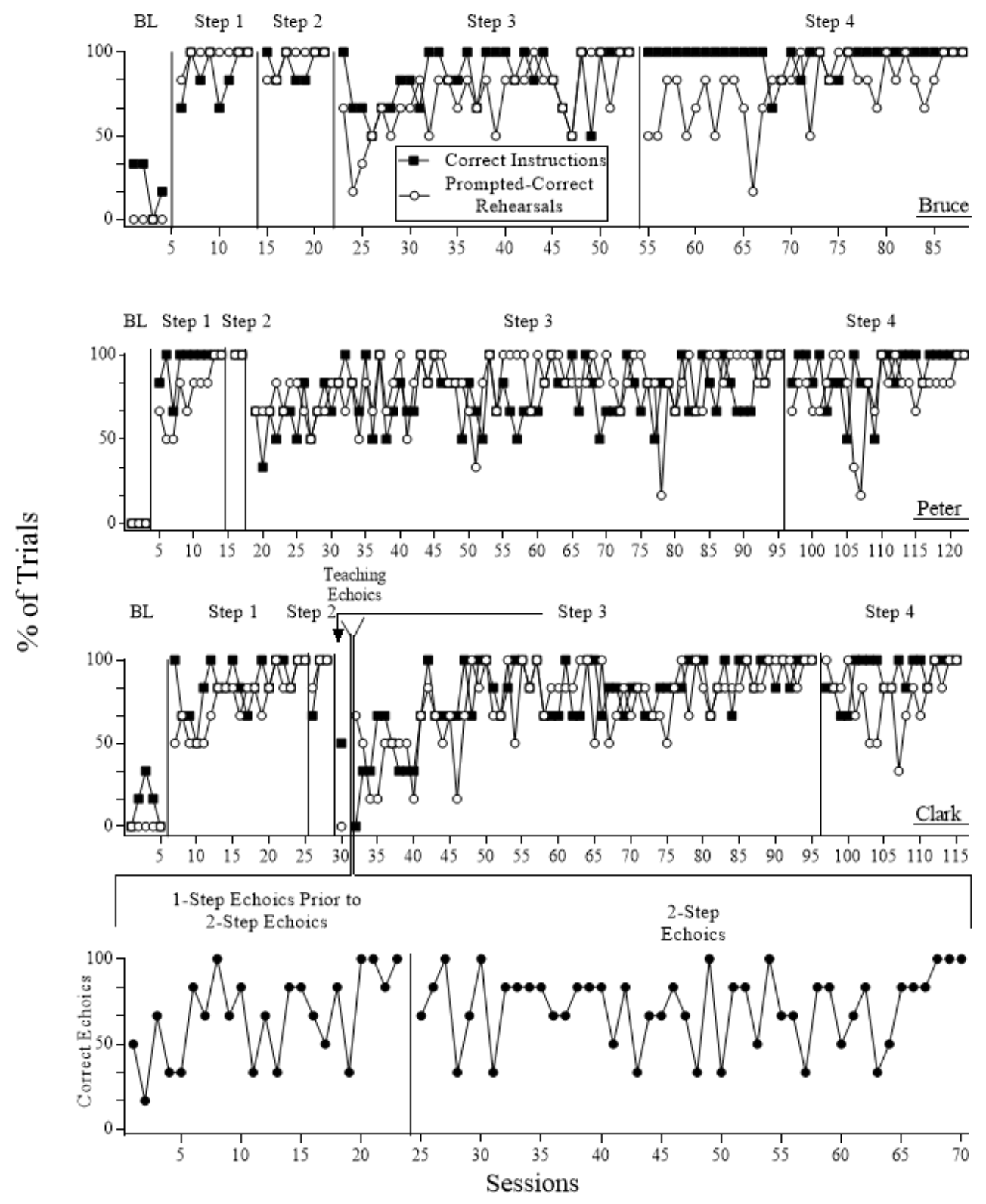

Figure 2. Bruce, Peter, and Clark's performance during teaching. Panel 4 depicts Clark's performance during echoic teaching.

After teaching-step 4, we assessed performance during postteaching (Figure 1; third phase). Unlike the delayed and gradual improvements reported by Causin et al. 
(2013), there was an immediate, robust improvement in completing two-step instructions across all three children. An immediate and robust improvement in first-trial performance would be expected after teaching responding under joint control in that, joint control is independent of any particular instruction but specific to the relations (i.e., rehearsals and tacts) between stimuli (Lowenkron, 1989). It is possible that the gradual improvements observed by Causin et al. could be explained by incorrect rehearsals; however, rehearsals were not measured making it difficult to interpret the results. Furthermore, we observed robust improvements in the completion of two-step instructions despite the challenging two-room arrangement, which required the children to listen to an instruction in one room and then transition to another room to locate the necessary objects among other objects. Transitioning from one setting to another delays the opportunity to respond to an instruction, which may weaken stimulus control, and introduces other stimuli (e.g., people walking in the hall, artwork on the walls, ambient noise from nearby offices) that may compete with, and thereby disrupt, the stimulus control of the instruction. Furthermore, because we programmed six two-step instructions per session and rotated different instructions across sessions, every trial in the first six sessions served as a test of first-trial performance with a novel two-step instruction (i.e., an instruction that has not contacted differential reinforcement). When restricting visual inspection to the postteaching sessions before Study 2 (dotted phase line), Bruce and Clark exhibited firsttrial performance on $24(80 \%)$ and $22(73 \%)$ of the 30 instructions, respectively, and Peter exhibited first-trial performance on 13 of the $18(72 \%)$ instructions. Similar levels of performance were obtained during postteaching after Study 2 (dotted phase line) was completed. Given the variability in prompted-correct rehearsals that preceded the return 
to postteaching for all children, it is not surprising instruction completion was less than perfect. Future research should employ more conservative criteria (e.g., four consecutive sessions with $100 \%$ prompted-correct rehearsals and instruction completion) to see if the variability in teaching-step 4 would decrease and, therefore, lead to nearly perfect instruction completion. All of the two-step instructions used in the present study produced a permanent product in that after instruction completion, one could view the objects included in the instructions and be able to report whether or not the instruction was completed correctly. Although we did not observe children looking around the room following instruction completion, it is unclear as to whether our results would have been as robust had we used instructions that did not leave a permanent product (i.e., Turn the knob four times and touch your toes).

During all postteaching sessions, there was high correspondence between correct rehearsals and instruction completion. Upon inspecting within-session performance (Fahmie \& Hanley, 2008), a correct instruction (a) never occurred when an incorrect rehearsal was scored and (b) occurred on 97\% of those trials when a correct rehearsal was scored. This correspondence between correct rehearsals and instructions is in line with the conceptualization of how the behavioral process of joint control facilitates first-trial performance. That is, rehearsing the instruction allowed children to maintain contact with the instruction as a verbal stimulus during delays and entered into joint control when objects were encountered which evoked tacts that shared that same topography of the rehearsed instruction. Moreover, our within-session analyses revealed that when children's rehearsals were incorrect, the children continued to respond correctly as a listener. That is, the type of incorrect rehearsal corresponded with the type of incorrect 
instruction. For example, during one trial in Bruce's first postteaching session, he rehearsed "Bring me plate; put sock in crib" instead of "Bring me plate; put sock under crib," and, when he entered the room, he completed the first instruction correctly but put the sock in the crib instead of under the crib.

During generalization tests, Bruce and Peter exhibited first-trial performance on $100 \%$ and $83 \%$ of the two-step instructions their mothers delivered at home, respectively, and Clark exhibited first-trial performance on $85 \%$ of the two-step instructions (18 of $21^{1}$ ) delivered by an unfamiliar adult in his classroom. Next, we taught Bruce and Peter to rehearse covertly (procedures available from the first author), and they continued to complete the instructions. During the six-week maintenance test, there were high levels of instruction completion that corresponded with correct echoic rehearsals. Bruce did not emit echoic rehearsals or complete instructions correctly during the first two trials of the maintenance test; after the second trial, he reported that he still needed to talk aloud to remember the instruction. Thereafter, Bruce independently emitted overt rehearsals in the remaining four trials and completed each of these instructions. Peter emitted overt rehearsals during every trial. This could have been due to the brief history of rehearsing covertly (i.e., we taught covert rehearsals in one day) relative to the extended history of rehearsing overtly. Unfortunately, Clark was unavailable to continue in the evaluation due to reasons unrelated to our study.

Prior to Study 1, all the children exhibited first-trial performance without a delay in completing instructions ("Hand me [object], [object], and [object]") as identified via the first part of our screening assessment, which indicated joint control served as a

\footnotetext{
${ }^{1}$ Three trials were removed due to procedural fidelity errors in the first two sessions.
} 
discriminable event. Therefore, we presumed if the children rehearsed the instructions over the 10-s delay, they would complete the instructions in teaching-step 1 (Figure 2, second phase), particularly given we used the same instructional frame ("Hand me [object], [object], and [object]"). However, this was not the case with two of three children. Returning to the screening assessment, the children listened to the instruction spoken by the experimenter immediately before the opportunity to hand over three objects in a sequence, and the experimenter's instruction served as a sufficient source of stimulus control to facilitate joint control (i.e., all children responded correctly on all five trials). In teaching-step 1, by contrast, the child's self-echoic rehearsal of the instruction preceded the opportunity to hand over three pictures after the cover over the objects was removed, and the rehearsed instruction did not reliably facilitate joint control. It is plausible the vocal behavior of the experimenter served as verbal stimuli but selfproduced vocal behavior served as a weaker source of stimulus control, which may especially apply to children with ASD who may not have an extensive learning history of responding to their own vocal behavior as a listener. In support of this interpretation, Esch et al. (2010) identified that children with ASD exhibited larger discrepancies between the number of numerals they could emit as echoics and self-echoic responses than in same-aged, neurotypical peers.

With Bruce and more noticeably Clark, there were multiple sessions with trials in which incorrect instructions occurred even though they engaged in prompted-correct rehearsals (closed boxes below 100\%). After a brief history of contacting differential reinforcement for responding to their self-echoic rehearsal as verbal stimuli in conjunction with tacting the objects in teaching-step 1, there was less variability in the 
percentage of instructions completed. Moreover, we were concerned our extended teaching of echoic rehearsals with Clark at teaching-step 3 would negatively affect rehearsals functioning as verbal stimuli because teaching took place in the absence of instruction completion. The initially low levels of instruction completion upon returning to teaching-step 3 provided tentative support for this concern. Given the critical role of self-echoic rehearsals in the emergence of completing two-step instructions in the current study, and the evidence children with ASD are more likely to have deficient self-echoic repertoires (Esch et al., 2010), it is important to establish (a) self-echoics and (b) selfechoics as verbal stimuli in children with ASD. Our study demonstrated a procedure to strengthen self-echoic rehearsals while simultaneously targeting the applied target of completing instructions.

Researchers should systematically replicate our teaching procedures with individuals who communicate nonvocally. Instead of echoic rehearsals, teaching hand signs and rehearsals to maintain stimulus control of the instruction over delays should facilitate the completion of multistep instructions via joint control. Similarly, Lowenkron (1988) taught individuals with intellectual disabilities to maintain a single hand sign over delays to facilitate joint control and produce delayed-identity matching across untaught targets. Although teaching the rehearsal of hand signs of two-step instructions would be more difficult than teaching an individual to maintain a single hand sign over a delay, procedures to teach rehearsals of hand signs should be investigated given the applied implications of teaching echoic rehearsals demonstrated in the present study. In addition to teaching rehearsals of the hand signs after hearing a vocal-verbal instruction, researchers could deliver instructions using sign language to individuals who exhibit 
hearing impairments. Our teaching procedures should be efficacious with either mode of instruction delivery (sign language or vocal-verbal).

\section{CHAPTER 2: Component Analysis of Joint Control}

We used a reversal design to demonstrate experimental control over the two sources of stimulus control posited to enter into joint control: Rehearsals of the instructions and tacts of the objects. We conducted the component analysis to provide an experimental, and falsifiable, analysis of joint control. That is, if one source of joint control is absent or disrupted and instruction completion continues to occur, joint control is not the behavioral process facilitating the performance. This study took place after the initial set of postteaching in-clinic measures in Study 1 (denoted by the dotted line in Figure 1).

\section{Preassessments}

Tact assessment to identify unknown objects. We identified 18 objects the child could not tact, described as unknown objects. We compiled a set of 30 relatively inexpensive objects ranging from office supplies to outdated gadgets (list is available from first author). We started with a receptive-discrimination assessment of the unknown objects; the procedures were identical with those described in the receptive discrimination of known objects in Study 1. Next, we assessed the same objects as tacts using the procedures described in the tact assessment in Study 1 to identify known objects, except we interspersed known tacts in a 3:1 ratio to promote continued responding. Any object the child tacted was not re-presented. We defined unknown objects as those for which incorrect responses in receptive-discrimination and tact assessments were obtained. After we identified 18 unknown objects, we asked parents 
and teachers not to teach the names of these objects.

Identifying a vocal response to interrupt echoic rehearsals. We asked caregivers and the child's early-intervention therapists to identify songs they had observed the child sing independently. We prompted the child to sing the song (e.g., "Let's sing the [ABC song]") and provided reinforcement following its completion. We selected a different song if the child did not independently sing it or sang too slowly (i.e., greater than $3 \mathrm{~s}$ between vocal utterances). Next, the child practiced singing while walking down the hallway twice to ensure the child would continue to sing while walking.

\section{Testing the Absence of Tacts on Correct Instructions}

Two-step instructions with known tacts. The procedures were identical with those used during postteaching in-clinic as described in Study 1.

Two-step instructions with unknown tacts. We tested whether the absence of tacts for the objects in the instructions would affect first-trial performance with instructions. The procedures were identical with postteaching with two exceptions. First, for intrasubject replication, the 18 unknown objects were divided into two sets; each sixtrial session included nine unknown objects. Unknown objects were assigned to only one of the instructional frames in each two-step instruction to promote continued rehearsal (see Table 4). Second, we walked throughout the room and prompted the child to tact all 36 objects (18 unknown objects and 18 known objects), even though only 9 of the 18 unknown objects were included in the session. Brief praise was provided on a fixed-ratio 2 schedule after a correct tact for a known object; the experimenter said "okay" after an incorrect tact to an unknown object. Of the 42 distractor objects present in Study 1, we 
replaced 18 with the unknown objects so 60 objects remained present throughout the room (18 unknown objects and 42 distractor objects).

Table 4

Example of Two Sessions in Two-Step Instructions with Unknown Tacts

\begin{tabular}{|c|c|c|}
\hline Trial & Session 1 & Session 2 \\
\hline 1 & "Bring me [oil]; Put [grapes] in [bag]." & "Put $[$ tulle $]$ on [koozie]; Pick up [spoon]." \\
\hline 2 & $\begin{array}{c}\text { "Take out }[\text { baby }] ; \text { Put }[\text { murse }] \text { under } \\
\{[\text { coaster }] . "\end{array}$ & "Pick up [record]; Put [grapes] on [chair]." \\
\hline 3 & "Pick up [spoon]; Put [tulle] on [breeder]." & "Put $[$ file $]$ under [breeder]; Take out [bag]." \\
\hline 4 & "Put [file] in [koozie]; Bring me [blanket]." & "Bring me [filter]; Put [dino] in [sink]." \\
\hline 5 & "Put [spoon] on [table]; Pick up [filter]." & "Take out [oil]; Put [cup] under [blanket]." \\
\hline 6 & $\begin{array}{c}\text { "Put }[\text { dino] under }[\text { chair }] \text {; Take out } \\
\text { [record }] . "\end{array}$ & "Put $[$ tulle $]$ in $[$ murse $]$; Bring me [drum]." \\
\hline
\end{tabular}

Note. The unknown tacts are boldface and italicized.

Teaching tacts of unknown objects. For both sets composed of nine unknown objects, we taught the child tacts for three objects at a time until all nine were learned. Each session included three objects and consisted of nine teaching trials; the presentation of the targets was randomized and balanced. We implemented errorless teaching ( 0 -s prompt delay) for two sessions and then implemented a 5-s prompt delay. The mastery criterion was $100 \%$ of trials with correct tacts across two consecutive sessions. After each of the three sets composed of three objects were mastered, we ended teaching with sessions in which each of the nine objects was presented on one trial. We combined all the nine targets to ensure tacts were at strength given we initially taught them 
sequentially (i.e., three objects at a time).

Two-step instructions with taught tacts. The procedures were identical with the procedures in two-step instructions with unknown tacts except tacts of the nine previously unknown objects had been taught (described as taught tacts).

\section{Testing the Interruption of Echoic Rehearsals on Correct Instructions}

We tested the effects of interrupting echoic rehearsals, the second source of stimulus control in joint control, on completing instructions. We delivered a two-step instruction, prompted the child to repeat the instruction, and immediately prompted the child to count in Spanish (Bruce) or sing the ABCs (Peter and Clark). If needed, we used the rehearsal prompt to ensure continuous counting or singing until the child entered the room where the objects necessary to complete the instruction were located. If over $3 \mathrm{~s}$ elapsed without counting or singing, the trial was restarted.

\section{Results and Discussion}

Bruce, Peter, and Clark's performance are depicted in Figure 3. The first phase depicts the same data as in postteaching in-clinic from Study 1 because it preceded the component analysis of joint control. Next, we included nine unknown tacts in the instructions (open diamonds), and the children did not engage in any instructions despite high levels of correct rehearsals. We replicated this outcome via a reversal design, which demonstrated functional control over the necessity of including objects that evoke tacts in the instructions and showed correct rehearsals alone were insufficient. In other words, without tacts of the objects, the stimulus control of the rehearsals did not enter into joint control because none of the objects in the room evoked tacts of the same topography of the objects rehearsed. 


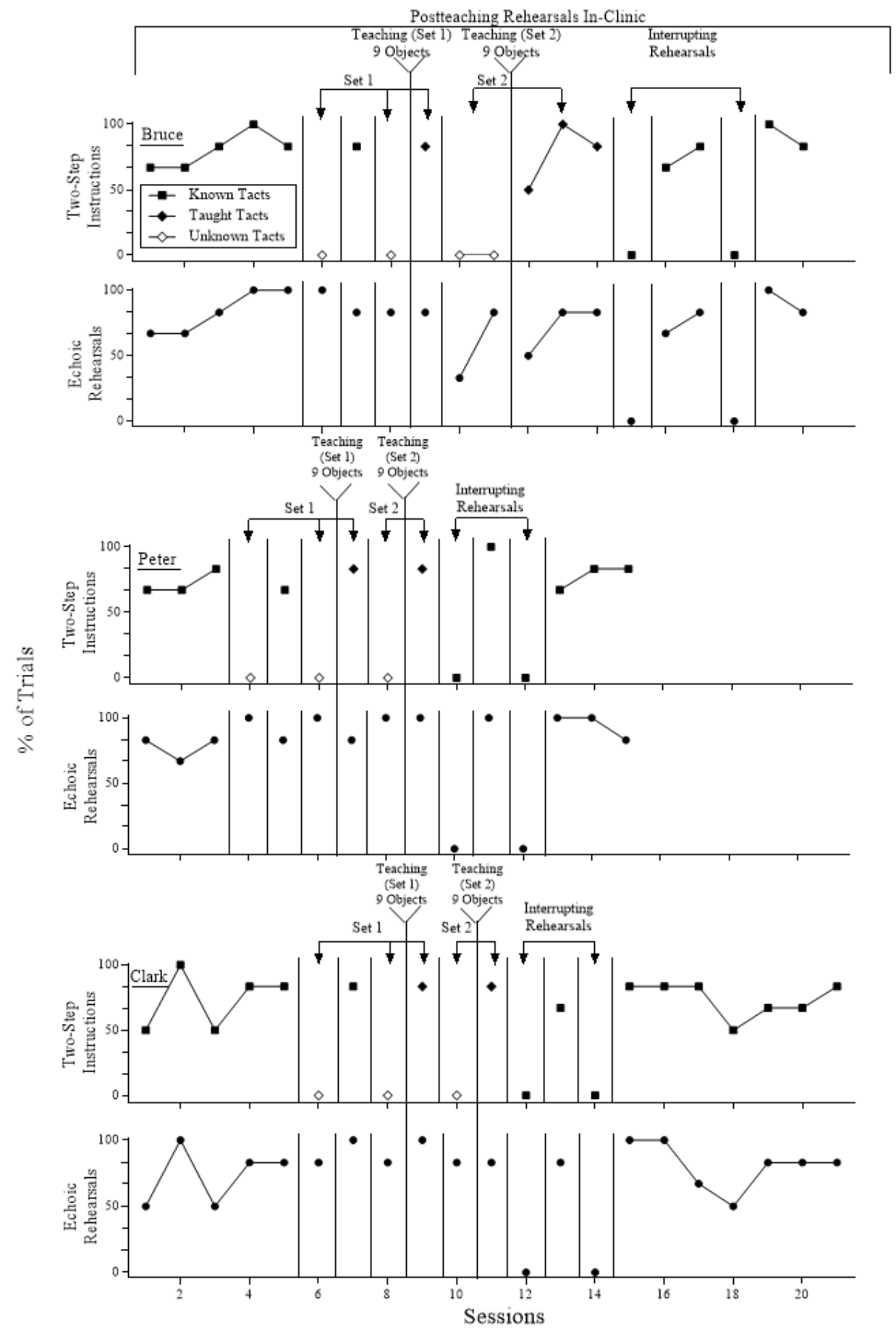

Figure 3. Bruce, Peter, and Clark's performance during Study 2. The first phase represents data from postteaching in-clinic during Study 1 because it preceded the component analysis. 
Next, we taught the children to tact the nine previously unknown objects (double phase lines) and assessed performance again. Children exhibited nearly perfect performance (closed diamonds; fifth phase). We replicated this outcome with the second set of nine objects (sixth and seventh phases). Because the children had never been asked to complete instructions with the 18 objects after learning to tact each, every trial with an instruction represents first-trial performance (all closed diamond sessions). First-trial performance occurred on $79 \%$ of trials for Bruce and $83 \%$ of trials for Peter and Clark (see white bars in Figure 4). We conducted a within-session analysis (Fahmie \& Hanley, 2008) that entailed counting the number of novel two-step instructions that each child completed during all postteaching sessions with known tacts across both studies and the number of novel two-step instructions that each child completed during Study 2 with taught tacts. Any instruction that was presented more than once was removed from the denominator (denoted by the horizontal black lines above each bar). If a child made an error during postteaching with known tacts, but completed the same instruction correctly on the second presentation, we did not count this as first-trial performance despite the fact that we did not teach the instruction nor did we use error correction. After teaching tacts of unknown objects, the children not only attended to the objects but also - for the first time - responded in a discriminated manner toward the object. That is, we demonstrated how the instructional frame altered how the child behaved toward the object. In addition, we showed that teaching children to respond under the joint control of their echoic rehearsals and tacting will facilitate the completion of novel instructions without a history of prompting, direct teaching, or reinforcement. 


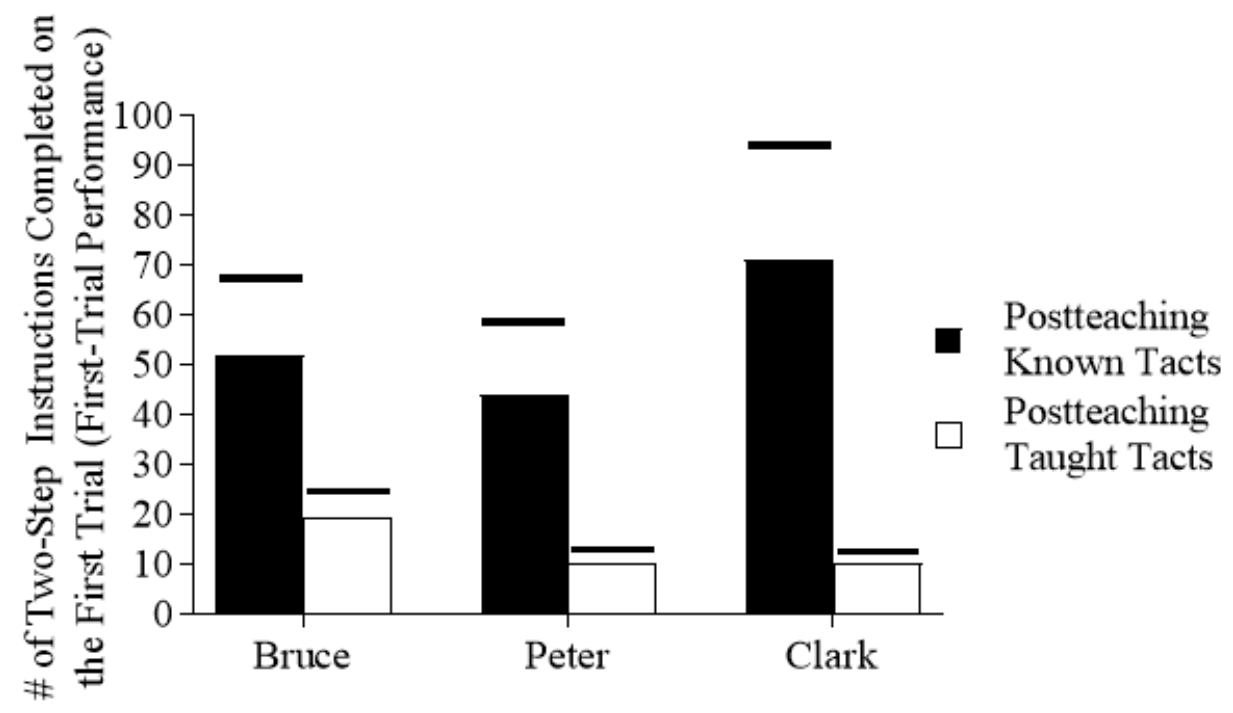

Figure 4. The number of two-step instructions completed on the first opportunity across all phases from Study 1 and Study 2 with known tacts (depicted by the black bars). The number of two-step instructions completed on the first opportunity with taught tacts in Study 2 (depicted by white bars). The maximum number of opportunities is depicted by the black horizontal line above each bar.

To test the influence of the other source of stimulus control, we interrupted echoic rehearsals by prompting children to count or sing until they entered the room. The children did not complete any instructions or correct rehearsals, and we replicated this outcome via a reversal design. This outcome indicates counting or singing effectively competed with rehearsal of the instruction and thereby blocked the stimulus control that would have been exerted by rehearsals, which rendered joint control absent. Results of the component analysis indicate first-trial performance in completing two-step instructions depended on both sources of joint control.

These results extend research on the effects of blocking echoic rehearsals on firsttrial performance with a sequencing task (Clough, Meyer, \& Miguel, 2016; DeGraaf \& Schlinger, 2012; Gutierrez, 2006). In these studies, adults were asked to sequence pictures when provided with either a three- or four-word spoken sequence of common 
household objects or arbitrary shapes in a foreign language or nonsense words. The experimenter disrupted rehearsal of the sequence by prompting competing responses similar to our study (i.e., singing songs or counting backward), and the effects of the competing responses interfering with joint control was convincingly shown with three of six adults in Gutierrez (2006), six of 10 adults in DeGraaf and Schlinger (2012), and 11 of 12 adults in Clough et al. (2016). Notice that prompting an overt competing response did not result in decrements in sequencing for every adult, and when there was a decrease in performance, correct sequencing was not eliminated. Rehearsals may be necessary only in certain situations. That is, rehearsals will likely be necessary when the instruction is complex (e.g., multiple steps), there are long delays to encountering the objects, or both.

Ratkos, Frieder, and Poling (2016) demonstrated overt rehearsals were not necessary for typically developing three- to six-year-old children to perform well on a delayed matching-to-sample task with up to 30-s delays between the sample stimulus and comparison stimuli. However, several procedures in Ratkos et al. deviated from related research. First, the target response involved identity matching instead of an arbitrary relation (e.g., auditory-visual conditional discriminations), which are typically used when assessing joint (echoic-tact) control. Second, the target response was selecting one common household item on each trial, and it is likely the children had a history of reinforcement for responding toward these items. It is possible that using pictures of common items (Gutierrez, 2006; DeGraaf \& Schlinger, 2012; Ratkos et al., 2016) makes the task easier and is more likely to evoke images of the pictures (i.e., conditioned seeing), thereby rendering the blocking of rehearsals less detrimental on performance. 
Third, although it was a delayed identity-matching task, the children also were prompted to tact the sample, which increased the likelihood a selection response occurred under joint control. That is, in past research, a picture is presented without requiring an overt tact because joint control does not require constant rehearsals between the presentation of the sample and the selection response, it only requires there be one (overt or covert) emission (Lowenkron, 1998; Palmer, 2006). It is unclear whether children would have failed the delayed matching-to-sample task if the researchers did not prompt the children to tact the sample stimulus, used a more complex response (e.g., selecting three cards in a sequence), or used arbitrary stimuli. Regarding the use of arbitrary stimuli, Clough et al. may have demonstrated the most convincing results with their disruption procedure (i.e., 11 of 12 the adults showed a decrease in performance) because the task involved nonsense words and arbitrary shapes. We selected action-object instructions as the target responses, instead of arbitrary stimuli, because we wanted a skill that would directly benefit the children. With that said, we arranged challenging preteaching and postteaching tests in that we used two-step instructions in an applied setting and targeted delays that were based on the time it took a typically developing child to complete a twostep instruction that required transitioning between two rooms.

Palmer (2006) suggested competing vocal behavior (e.g., singing) may decrease performance by distracting the participant rather than interfering with covert rehearsals in a way that prevents joint control. Clough et al. (2016) asked participants to report strategies they used during the sequencing tasks, and all participants' indicated they covertly repeated the names of the sequences dictated by the experimenter but struggled doing so when prompted to emit competing vocal behavior. This suggested covert 
rehearsals were blocked. Clough et al.'s Study 3 included a control-sequencing test that could be completed without vocal rehearsals to determine whether an incompatible vocal response disrupts performance on emergent vocal sequencing because it prevented rehearsal or served as a distraction. The control-sequencing tests were identical with the vocal-sequencing tests described in Study 1, except a second set of cards were presented in the sequence stated by the experimenter before each trial (i.e., identity match prompt). During baseline, all participants accurately sequenced the cards when the matching sequence was provided and made incorrect responses when the matching sequence was absent. After echoic and tact training, all participants sequenced the arbitrary stimuli on $\geq$ 4 of 5 trials. Performance remained high when the matching sequence was provided regardless of whether the incompatible vocal response was in place. The performance of all participants' decreased when the matching sequence was not provided, which indicated the incompatible vocal response disrupted performance on emergent sequencing because it prevented rehearsal and did not simply serve as a distraction. Given the outcomes in translational research (Clough et al., 2016; DeGraaf \& Schlinger, 2012; Gutierrez, 2006) and in our study, future researchers do not need to show that disrupting echoic rehearsals prevents joint control and, thus, the target response in applied research.

\section{General Discussion}

We taught children with ASD to leverage joint control by rehearsing spoken instructions over delays in order to complete novel two-step instructions of applied significance. We showed the effects of our teaching also led to response generalization of performance in applied contexts and maintenance over time. These outcomes notably 
extend applied research (Frisch \& Schumaker, 1974; Striefel et al., 1976; Whitman et al., 1971) in several important ways. This is the first study to demonstrate the efficacy of procedures to promote the completion of multistep instructions with delays. These outcomes support practitioners using our teaching procedures to help children complete novel instructions that involve delays. Preparing children to complete common multistep instructions promotes independence at home and in inclusive educational classrooms. 


\section{References}

Atwater, J. B., \& Morris, E. K. (1988). Teachers' instructions and children's compliance in classrooms: A descriptive analysis. Journal of Applied Behavior Analysis, 21, 157-167. https://doi.org/10.1901/jaba.1988.21-157

Beaulieu, L., Hanley, G. P., \& Roberson, A. A. (2012). Effects of responding to a name and group call on preschoolers' compliance. Journal of Applied Behavior Analysis, 4, 685-707. https://doi.org/10.1901/jaba.2012.45-685

Beaulieu, L., \& Hanley, G. P. (2014). Effects of a classwide teacher-implemented program to promote preschooler compliance. Journal of Applied Behavior Analysis, 47, 594-599. https://doi.org/10.1002/jaba.138

Causin, K. G., Albert, K. M., Carbone, V. J., \& Sweeney-Kerwin, E. J. (2013). The role of joint control in teaching listener responding to children with autism and other developmental disabilities. Research in Autism Spectrum Disorders, 7, 997-1011. https://doi.org/10.1016/j.rasd.2013.04.011

Clough, C. W., Meyer, C. S., \& Miguel, C. F. (2016). The effects of blocking and joint control training on sequencing visual stimuli. The Analysis of Verbal Behavior, 32, 242-264. https://doi.org/10.1007/s40616-016-0067-1

DeGraaf, A., \& Schlinger, H. D. (2012). The effect of joint control training on the acquisition and durability of a sequencing task. The Analysis of Verbal Behavior, 28, 59-71. https://doi.org/10.1007/BF03393107

DeLeon, I. G., \& Iwata, B. A. (1996). Evaluation of a multiple-stimulus presentation format for assessing reinforcer preferences. Journal of Applied Behavior Analysis, 29, 519-533. https://doi.org/10.1901/jaba.1996.29-519 
Esch, J. W., Esch, B. E., McCart, J. D., \& Petursdottir, A. I. (2010). An assessment of self-echoic behavior in young children. The Analysis of Verbal Behavior, 26, 313. https://doi.org/10.1007/BF03393078

Esch, J. W., Mahoney, A.M., Kestner, K.M., LaLonde, K.B., \& Esch, B.E. (2013). Echoic and self-echoic responses in children. The Analysis of Verbal Behavior, 29, 117-123. https://doi.org/10.1007/BF03393129

Fahmie, T. A., \& Hanley, G. P. (2008). Progressing toward data intimacy: A review of within-session data analysis. Journal of Applied Behavior Analysis, 41, 319-331. https://doi.org/10.1901/jaba.2008.41-319

Frisch, S. A., \& Schumaker, J. B. (1974). Training generalized receptive prepositions in retarded children. Journal of Applied Behavior Analysis, 7, 611-621. https://doi.org/10.1901/jaba.1974.7-611

Gutierrez, R. D. (2006). The role of rehearsal in joint control. The Analysis of Verbal Behavior, 22, 183-190. https://doi.org/10.1007/BF03393038

Hoerger, M. L., \& Mace, F. C. (2006). A computerized test of self-control predicts classroom behavior. Journal of Applied Behavior Analysis, 39, 147-159. https://doi.org/10.1901/jaba.2006.171-04

Lin, H. L., Lawrence, F. R., \& Gorrell, J. (2003). Kindergarten teachers' views of children's readiness for school. Early Childhood Research Quarterly, 18, 225237. https://doi.org/10.1016/S0885-2006(03)00028-0

Lowenkron, B. (1984). Coding responses and the generalization of matching to sample in children. Journal of the Experimental Analysis of Behavior, 42, 1-18. https://doi.org/10.1901/jeab.1984.42-1 
Lowenkron, B. (1988). Generalization of delayed identity matching in retarded children. Journal of the Experimental Analysis of Behavior, 50, 163-172. https://doi.org/10.1901/jeab.1988.50-163

Lowenkron, B. (1989). Instructional control of generalized relational matching to sample in children. Journal of the Experimental Analysis of Behavior, 52, 293-309. https://doi.org/10.1901/jeab.1989.52-293

Lowenkron, B. (1998). Some logical functions of joint control. Journal of the Experimental Analysis of Behavior, 69, 327-354. https://doi.org/10.1901/jeab.1998.69-327

Lowenkron, B. (2006). Joint control and the selection of stimuli from their description. The Analysis of Verbal Behavior, 22, 129-151. https://doi.org/10.1007/BF03393035

Ndoro, V. W., Hanley, G. P., Tiger, J. H., \& Heal, N. A. (2006). A Descriptive Assessment of Instruction-Based Interactions in the Preschool Classroom. Journal of Applied Behavior Analysis, 39, 79-90. http://doi.org/10.1901/jaba.2006.146-04

Palmer, D. C. (2004). Data in search of a principle: a review of Relational frame theory: a post-Skinnerian account of human language and cognition. Journal of the Experimental Analysis of Behavior, 81, 189-204. https://doi.org/10.1901/jeab.2004.81-189

Palmer, D. C. (2006). Joint control: A discussion of recent research. The Analysis of Verbal Behavior, 22, 209-215. https://doi.org/10.1007/BF03393040

Partington, J. (2006). Assessment of basic language and learning skills-revised (The 
ABLLS-R). Pleasant Hill: Behavior Analysts.

Ratkos, T., Frieder, J. E., \& Poling, A. (2016). Accurate delayed matching-to-sample responding without rehearsal: an unintentional demonstration with children. The Analysis of Verbal Behavior, 32, 69-77. https://doi.org/10.1007/s40616-016-00528

Skinner, B. F. (1957) Verbal behavior. New York; Appleton-Century-Crofts.

Stephenson, K. M. \& Hanley, G. P. (2010). Preschoolers' compliance with simple instructions: a descriptive and experimental evaluation. Journal of Applied Behavior Analysis, 43, 229-247. https://doi.org/10.1901/jaba.2010.43-229

Striefel, S., Wetherby, B., \& Karlan, G. R. (1976). Establishing generalized verb-noun instruction-following skills in retarded children. Journal of Experimental Child Psychology, 22, 247-260. https://doi.org/10.1016/0022-0965(76)90005-9

Sundberg, M. L., \& Sundberg, C. A. (2011). Intraverbal behavior and verbal conditional discriminations in typically developing children and children with autism. The Analysis of Verbal Behavior, 27, 23-43. https://doi.org/10.1007/BF03393090

Sy, J. R., Donaldson, J. M., Vollmer, T. R., \& Pizarro, E. (2014). An evaluation of factors that influence children's instruction following. Journal of Applied Behavior Analysis, 47, 101-112. https://doi.org/10.1002/jaba.94

Whitman, T. L., Zakaras, M., \& Chardos, S. (1971). Effects of reinforcement and guidance procedures on instruction-following behavior of severely retarded children. Journal of Applied Behavior Analysis, 4, 283-290.

https://doi.org/10.1901/jaba.1971.4-283 